\title{
Comparative GC-MS Analysis of Bioactive Phytochemicals from Different Plant Parts and Callus of Leptadenia reticulata Wight and Arn.
}

\author{
Priyanka Godara, Bunty Kumar Dulara, Neelam Barwer, Navneet Singh Chaudhary*
}

\section{Priyanka Godara, Bunty Kumar Dulara, Neelam Barwer, Navneet Singh Chaudhary*}

Department of Botany, University of Rajasthan, JLN Marg, Jaipur-302004, Rajasthan, INDIA.

\section{Correspondence}

\section{Dr. Navneet Singh Chaudhary}

Assistant Professor,

Department of Botany University of Rajasthan, JLN Marg, Jaipur-302004, Rajasthan, INDIA.

Phone no : +919468566695

E-mail: navneetiitr@gmail.com

History

- Submission Date: 20-08-2018;

- Review completed: 15-10-2018.

- Accepted Date: 15-11-2018

DOI : 10.5530/pj.2019.1.22

Article Available online http://www.phcogj.com/v11/i1

\section{Copyright}

(c) 2019 Phcog.Net. This is an openaccess article distributed under the terms of the Creative Commons Attribution 4.0 International license.

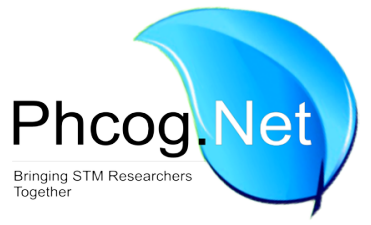

\begin{abstract}
Aim: The aim of this study is identification and comparative analysis of bioactive phytochemicals present in methanol and ethyl acetate extracts of different plant organs and callus of Leptadenia reticulata by GC-MS technique. Methodology: The shade dried plant samples (leaves stem and root) and callus produced from leaf of L. reticulata were powdered and then sequentially extracted in methanol and ethyl acetate solvents. Total eight extracts were prepared which were Methanolic Leaf Extract (MLE), Methanolic Stem Extract (MSE), Methanolic Root Extract (MRE), Methanolic Callus Extract (MCE), Ethyl Acetate Leaf Extract (EALE), Ethyl Acetate Root Extract (EARE), Ethyl Acetate Stem Extract (EASE) and Ethyl Acetate Callus Extract (EACE). Then, each of the extracts was further subjected to Gas ChromatographyMass Spectrometry (GC-MS) analysis. Results: The GC-MS analysis of the eight extracts revealed the presence of 77 different types of high and low molecular weight phytochemicals and bioactive compounds in varying quantities. Some of the phytochemicals detected for first time in L. reticulata are $\gamma$-sitosterol, Campesterol, Pristane, Hexahydrofarnesol, Stearic acid, Arachidic acid, Coniferyl alcohol, n-Tetracosanol-1, Ascorbic acid 2,6-dihexadecanoate, (2S,3S)-3,7,4'-Trihydroxy-5-methoxy-6-methylflavanone etc. These chemical compounds are considered biologically active and pharmacologically important. Conclusion: This study gives a detailed comparison of detection and identification of various bioactive phytochemicals from different plant parts (leaves, stem and root) and callus of L. reticulata. This provides a basis for the biological and biochemical characterization of some newly detected biologically and pharmacologically important phytochemical components from this plant.

Key words: Callus, Fatty Acid, Root, Stem, Steroids, Terpenoids.
\end{abstract}

\section{INTRODUCTION}

Phytochemicals present in medicinal plants have been part of phytomedicines since ancient times. Medicinal plants play a vital role in the prevention and treatment of various diseases and largely contributing in all existing prevention strategies. Various plant-based medicines have already proved their potential efficacy and safety. ${ }^{1}$ Now a days, synthetic drugs are broadly used but their extreme use may cause severe side effects in body which are sometimes more serious than that of disease itself. Hence, pharmaceutical companies are spending a lot of money and time on the plants with potential medicinal properties for the formulation of the natural drugs which are safe and effective. ${ }^{2}$ In developing countries all over the world, large number of people do not have access to synthetic drugs or they do not have potential to buy them, they still depend on traditional medicinal plants as they are cheaper and easily accessible. These reasons might account for the worldwide attention and use of medicinal plants. In 2013,
WHO prepared and lunched 'WHO Traditional Medicine Strategy 2014-2023' which emphasized to join together traditional and complementary medicine to promote universal healthcare and to ensure the safety, quality and effectiveness of such medicines. ${ }^{3}$

Approximately $20 \%$ of the plants found in the world have undergone pharmaceutical or biological tests. ${ }^{4}$ Plants have the ability to produce a number of compounds in the form of secondary metabolites that have diverse biological properties and they serve as active drugs against various diseases. ${ }^{2,5}$ Amount of these secondary metabolites varies from species to species and plant to plant depending on the age and variations in climates and ecological factors. ${ }^{2}$ The phytochemical accumulation in plants has generated understanding for the production of desired bioactive compounds with the prospective to produce desired component. In many 
cases, crude extracts from medicinal plants are more biologically active than isolated compounds due to their synergistic effects. ${ }^{6}$ Extraction and characterization of numerous bioactive compounds from these green plant factories have given birth to various high activity profile drugs. A number of different solvent systems like water, methanol, ethanol, chloroform, methanol, ethyl acetate, petroleum ether etc. have been reported to play important role for extraction of secondary metabolites, such as tannins, terpenoids, steroids, alkaloids, flavanoids, phenols and quinines. $^{2}$

Leptadenia reticulata Wight and Arn. (Asclepiadaceae) is a well-known tonic and life giving drug with rejuvenating, restorative, antiabortificent and lactogenic properties. It is a perennial woody climber called as 'Jeevanti' in Ayurveda which means 'life-giver' because it works as a stimulant and claimed to prevent miscarriage. ${ }^{7.8}$ Jeevanti is used in Ayurveda since $4500 \mathrm{BC}$ as a general body vigor provider. According to Atharva-Veda this plant promotes vitality and life. ${ }^{7}$ L. reticulata grows well in tropical and subtropical climate with moderate rainfall and relative humidity. This plant is also found in arid regions with sandy soil, low organic matter and very low rainfall. ${ }^{9}$ In India, L. reticulata is found in Sikkim, Karnataka, Rajasthan, Gujarat, Khasia hills, Nilgiris, Tamil Nadu, Laccadive Islands, Andhra Pradesh, Goa, Haryana, Kerala, Madhya Pradesh, Maharashtra, Orissa, Bihar, the sub-Himalayan tracts of Punjab, U.P. and Deccan Peninsula up to an altitude of 900 meters. ${ }^{8,10}$ Apart from India, it is distributed in the tropical and subtropical parts of Africa, Cambodia, Mauritius, Sri Lanka, Burma, Nepal, Madagascar, Malay Peninsula, the Philippines etc. ${ }^{10,11}$ L. reticulata has many biological activities like antiabortifacient, ${ }^{12}$ galactagogue/lactogenic/milk increasing effect, ${ }^{13}$ anti-implantation, ${ }^{14}$ antimicrobial, antioxidant, ${ }^{15}$ antitumour, ${ }^{16}$ immunomodulatory activity, ${ }^{17}$ antiepileptic potential, ${ }^{18}$ analgesic, ${ }^{9}$ antipyretic, anti-inflammatory, ${ }^{19}$ hepatoprotective, ${ }^{20}$ antiulcer, ${ }^{21}$ anxiolytic, ${ }^{22}$ diuretic, ${ }^{23}$ cardioprotective, ${ }^{24}$ antianaphylactic, antiasthmatic, antidepressant, vasodialator and hypotensive effects. ${ }^{9}$ It is also used in the treatment of oligospermia, aphrodisiac, infertility and benign prostatic hyperplasia. The leaves and roots are used in tuberculosis, cough and against skin infections such as ringworm and wounds. ${ }^{8}$ The therapeutic potential of this herb is because of the presence of organic acids, flavonoids, triterpenes, steroids, volatiles, amino acids, glucosides, tannins, inorganic ions and lignanoids. ${ }^{9}$ Thus, $L$. reticulata is a widely distributed plant with immense therapeutic potential. These properties demand a thorough phytochemical analysis, evaluation and validation of this herbal drug for natural product development.

In the current literature available, it is observed that most of the studies are focused on either aerial part or in the whole plant of L. reticulata, there are no reports found on the complete phytochemical analysis of different plant parts (leaf, stem and root) separately of $L$. reticulata using methanol and ethyl acetate solvents. Besides, there is also lacking reports on the comprehensive phytochemical analysis on tissue culture (in vitro) callus samples generated from this plant. Therefore, this study is focused to evaluate and analyze plant parts and callus extracts of L. reticulata for the presence of phytoconstituents in order to identify and characterize bioactive compounds in the crude extracts prepared in both solvents (methanol and ethyl acetate) for chemical profiling by Gas Chromatography-Mass Spectrometric (GC-MS) technique. The GC-MS is normally used for direct analysis of unknown components existing in traditional medicines and medicinal plants. The results pertaining to GC-MS analysis have led to identification of number of bioactive compounds from $L$. reticulata sample extracts. They were identified through mass spectrometry attached with GC. This study revealed the accumulation pattern of many known bioactive compounds in different plant parts of $L$. reticulata and detected many new bioactive compounds which were not earlier reported in this plant.

\section{MATERIALS AND METHODS}

\section{Instrument and Chemicals}

GC-MS System (Thermo scientific GC 1300 and TSQ 8000 Triple quadrupole), Soxhlet apparatus (3840, Borosil Glass works Ltd., Mumbai, India), Murashige and Skoog Medium PT-100, 1-Napthalene acetic acid (NAA) (Himedia), 2,4-Dichlorophenoxyacetic acid (2,4-D) (Duchefa Biochemie), Methanol (Rankem) and Ethyl Acetate (Loba Chemie). All other chemicals and reagent were used of Analytical and Biological grade.

\section{Collection of Plant Sample}

The fresh plant parts of $L$. reticulata were collected (Priyanka Godara; March 20, 2015) from nearby area of Jaipur, Rajasthan, India. The identity of collected plant specimen was confirmed by depositing the voucher specimen number RUBL211619 in the herbarium of Department of Botany, University of Rajasthan, Jaipur. The plant parts were washed thoroughly with water to remove dust and dried under the shade at room temperature for approximately 15 days till constant dry weight. The dried plant parts were separately ground in liquid nitrogen to obtain the fine powder and kept in an air tight container till further use.

\section{Callus Preparation}

The desired amount of callus was produced by sub-culturing of primarily produced callus from leaf explants of $L$. reticulata on MS media supplemented with standardized amount of growth regulators i.e. 2,4-D $(1.25 \mathrm{mg} / \mathrm{l})+\mathrm{NAA}(0.25 \mathrm{mg} / \mathrm{l})$.

\section{Preparation of Extracts}

The dried and fine powdered samples (leaves, roots, stem and callus) of L. reticulata exhaustively extracted with solvents methanol and ethyl acetate. $10 \mathrm{~g}$ of each powdered plant materials (leaves, stem and roots) and $4 \mathrm{~g}$ of callus were packed in thimbles (each in duplicate). Each sample was extracted in methanol and ethyl acetate $(100 \mathrm{ml}$ each) separately using Soxhlet apparatus as per standard method. The Soxhlet extracted plant samples were vacuum evaporated using Rotary Vacuum Evaporator (BR Biochem- Scilogex RE100-Pro) to obtain eight dried solid extracts. These extracts were named as Methanolic Leaf Extract (MLE), Methanolic Stem Extract (MSE), Methanolic Root Extract (MRE), Methanolic Callus Extract (MCE), Ethyl Acetate Leaf Extract (EALE), Ethyl Acetate Stem Extract (EASE), Ethyl Acetate Root Extract (EARE) and Ethyl Acetate Callus Extract (EACE). The percent yield of extracts was 9.6\% for MLE, 8.7\% for MSE, 5.8\% for MRE, 4.3\% for MCE, 5.1\% for EALE, $4.7 \%$ for EASE, $2.8 \%$ for EARE and $2.6 \%$ for EACE. All extracts were stored in vacuum tight container at $4^{\circ} \mathrm{C}$ in the refrigerator for further use.

\section{GC-MS Analysis}

The GC-MS analysis of $L$. reticulata dried and filtered extracts were carried out on a Thermo GC 1300 and TSQ 8000 Triple Quadrupole GC-MS system installed with auto sampler Al 1310. The program was set using capillary column TG-5MS AMINE $(30 \mathrm{~mm} \times 0.25 \mathrm{~mm}$; film thickness $0.25 \mu \mathrm{m}$ ) with initial temperature set to $70^{\circ} \mathrm{C}$ for $1 \mathrm{~min}$, then gradually increases at $4^{\circ} \mathrm{C} / \mathrm{min}$ up to $270^{\circ} \mathrm{C}$ with holding time of $1 \mathrm{~min}$. The injector temperature was set at $280^{\circ} \mathrm{C}$ and the carrier gas used was helium at a flow rate of $1.0 \mathrm{ml} / \mathrm{min}$. GC-MS analysis was conducted using TSQ8000 with transfer line temperature $280^{\circ} \mathrm{C}$ and ion source temperature $230^{\circ} \mathrm{C}$ in EI mode. The MS scan parameters included electron impact ionization voltage of $70 \mathrm{eV}$ and a mass range of $50-500 \mathrm{~m} / \mathrm{z}$. TSQ 8000 Triple Quadrupole MS detector was used for analysis and data was evaluated using total ion count (TIC) for compound identification and quantification. 


\section{Identification of Bioactive Phytochemicals}

Phytochemical compounds extracted in different extracts of L. reticulata were identified by comparing the mass spectra of the detected components with the mass spectral data of known components available in the National Institute of Standards and Technology (NIST) library. Compound concentrations were calculated from the GC peak areas of the total ion current (TIC).

\section{RESULTS}

The GC-MS chromatograms spectra obtained for all eight extracts revealed that $L$. reticulata is plenteously rich in bioactive compounds in all parts of plant as well as in callus (Figure 1). Each spectrum of extract shows the retention time in the column and the detected peaks correspond to the relative abundance of bioactive compounds detected in the particular extract. A total of 77 major phytochemical compounds were detected in leaves, stem, root and callus of $L$. reticulata extracted both in methanol and ethyl acetate. The name, molecular formula and the abundance of these bioactive compounds are presented in Table 1. The GC-MS chromatogram of leaf extract in methanol (MLE) and ethyl acetate (EALE) indicated the presence of 31 and 22 compounds respectively. Based on the abundance, in MLE and EALE major compounds were1-Tridecene (23.73\%), Phytol acetate (13.90\%), [6-hydroxy-2,2,6-
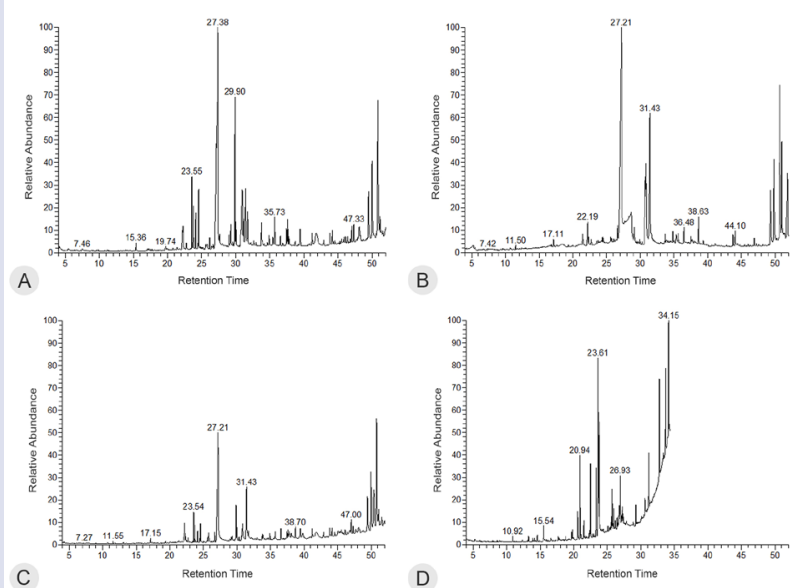

C
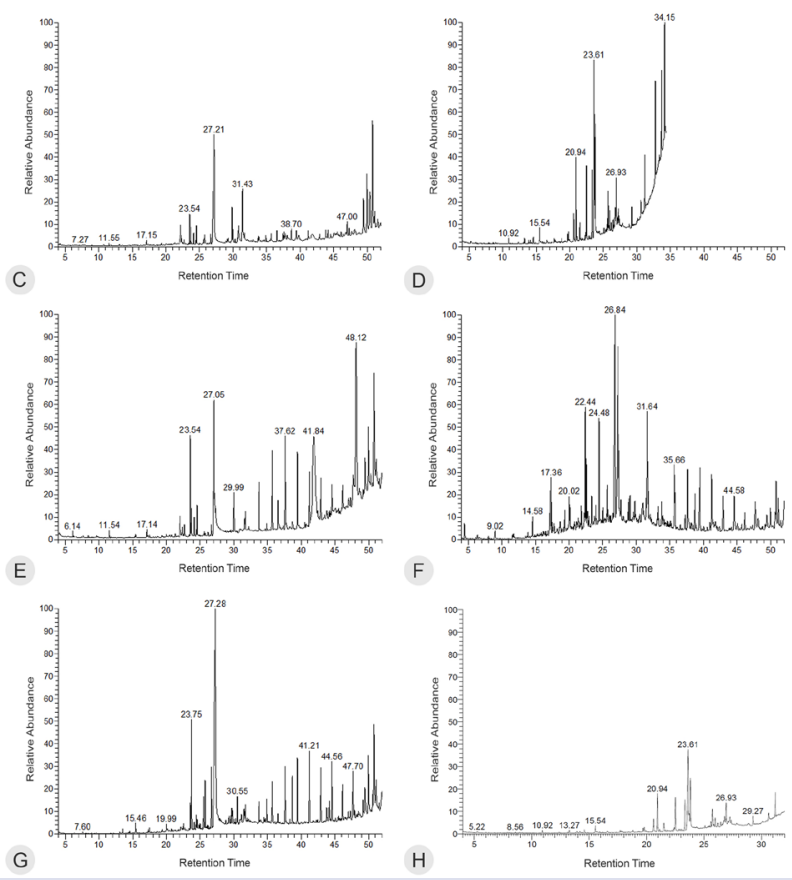

Figure 1: The GC-MS chromatograms of all eight extracts of Leptadenia reticulata showing relative abundance and retention time of phytochemicals. A: Methanolic Leaf Extract (MLE), B: Methanolic Root Extract (MRE), C: Methanolic Stem Extract (MSE), D: Methanolic Callus Extract (MCE), E: Ethyl Acetate Leaf Extract (EALE), F: Ethyl Acetate Root Extract (EARE), G: Ethyl Acetate Stem Extract (EASE), H: Ethyl Acetate Callus Extract (EACE). trimethyl-3-(3-methylbut-2-enyl)cyclohexyl]methyl acetate (13.36\%), $\beta$-sitosterol (9.27\%), Palmitic acid (8.44\%), 3,7,11-trimethyl-1-dodecanol (7.76\%), $\gamma$-Sitosterol (6.86\%), Stigmasterol $(4.79 \%$ and $3.65 \%)$ and Campesterol (3.12\% and 2.80\%). Moreover, methanolic root extract (MRE) and ethyl acetate root extract (EARE) detected for the presence of 26 and 29 major bioactive compounds respectively. The most abundant were l-(+)-Ascorbic acid 2,6-dihexadecanoate (18.66\%), Dibutyl phthalate (15.42\%), $\gamma$-Sitosterol (12.54\%), Stearic acid (10.50\%), 10-Heneicosene (8.71\%), $\beta$-amyrin (6.65\%), Stigmasterol (6.04\%), E-15-Heptadecenal (5.28\%), n-Tetracosanol-1 (5.08\%) and Campesterol (4.20\%). In addition, 31 and 25 major phytochemicals were identified in stem extracts of both methanol (MSE) and ethyl acetate extracts (EASE) respectively. The most abundant compounds detected in both extracts were $1-(+)$-Ascorbic acid 2,6-dihexadecanoate $(15.95 \%$ and $17.55 \%)$ followed by $\beta$-sitosterol (13.40\%), Methyl 8-oxo-17-octadecene-9,11-diynoate (7.51\%), Stigmasterol (6.71\%), $\gamma$-Sitosterol (6.35\%), Hexahydrofarnesyl acetone (5.77\%) and Campesterol (4.32\%)

The callus obtained from leaf explant of L. reticulata and its subsequent extraction in methanol (MCE) and ethyl acetate (EACE) solvents followed by GC-MS analysis, brought out that callus cells also expresses the bioactive phytochemicals in good amount. The GC-MS chromatogram of both MCE and EACE revealed the presence of 23 and 19 major bioactive compounds respectively. The major compound detected in both MCE and EACE extracts were 1-(+)-Ascorbic acid 2,6-dihexadecanoate $(16.18 \%$ and $20.78 \%)$ followed by Palmitic acid ethyl ester $(6.70 \%$ and $8.60 \%)$, Eicosane (8.04\%), Hexahydrofarnesyl acetone (7.24\%), Palmitic acid methyl ester (5.14\% and 6.61\%) and Phthalic acid, di(2-propylpentyl) ester (5.88\%).

\section{DISCUSSION}

Leptadenia reticulata is one of the major ingredients in many commercial herbal formulations including Confido (Speman forte), Galactin Vet (bolus), Safe herbs, Speman, Envirocare, Calshakti, Antisept and Chyawanprash. Presence of flavonoids, phytosterols, terpenes and terpenoids, fatty acids, tannins, carbohydrates, glycosides, saponins, free catechols, starches and phenolic compounds was identified by various researchers in different solvent extracts of $L$. reticulata. ${ }^{9}$ This plant has multiple therapeutic activities due to presence of various bioactive phytochemicals like stigmasterol, ß-sitosterol, a-amyrin, $ß$-amyrin, rutin, simiarenol, apigenin, reticulin, deniculatin, leptaculatin, l- $\alpha$-tocopherol, p-coumaric acid, quercetin, phytol etc. ${ }^{8}$ Present study gives a comparative account of various phytochemicals identified by GC-MS analysis in root, stem, leaves and callus. The comparative GC-MS analysis of plant parts and callus identified various classes of bioactive compounds that include steroids, terpenes, terpenoids, fatty acids and their esters, alcoholic and phenolic compounds, esters, hydrocarbons, coumarins, flavanoids, vitamin $\mathrm{C}$ and ketones (Table 1).

The bioactive compounds reported for the first time in $L$. reticulata through the present study are from group of Steroids ( $\gamma$-sitosterol, Campesterol, Campesterol acetate, Stigmastan-3,5-diene, Cholesteryl Myristate, etc.), Terpenes (Pristane, Hexahydrofarnesol, Hexahydrofarnesyl acetone, Phytol acetate etc.), Fatty acids and their esters (Stearic acid, Arachidic acid, Isopropyl myristate, Linolenic acid ethyl ester, Hexadecanoic acid methyl ester, Linolenic acid methyl ester), Esters (Dibutyl phthalate, Phthalic acid Diisobutyl ester), Phenolic compounds (Coniferyl alcohol and 2-(2-hydroxypropan-2-yl)-4-methoxy-5-methyl phenol), Alcoholic compounds (n-Tetracosanol-1, Montanol, Quercitol, 2-Methyl-Z,Z-3,13-octadecadienol and Trans-9-hexadecen-1-ol), a Vitamin C fatty acid compound (Ascorbic acid 2,6-dihexadecanoate), a Coumarin compound (2-Isopropyl-5-methylcyclohexyl 3-(1-(4chlorophenyl)-3-oxobutyl)-coumarin-4-yl carbonate), a flavanoidal 


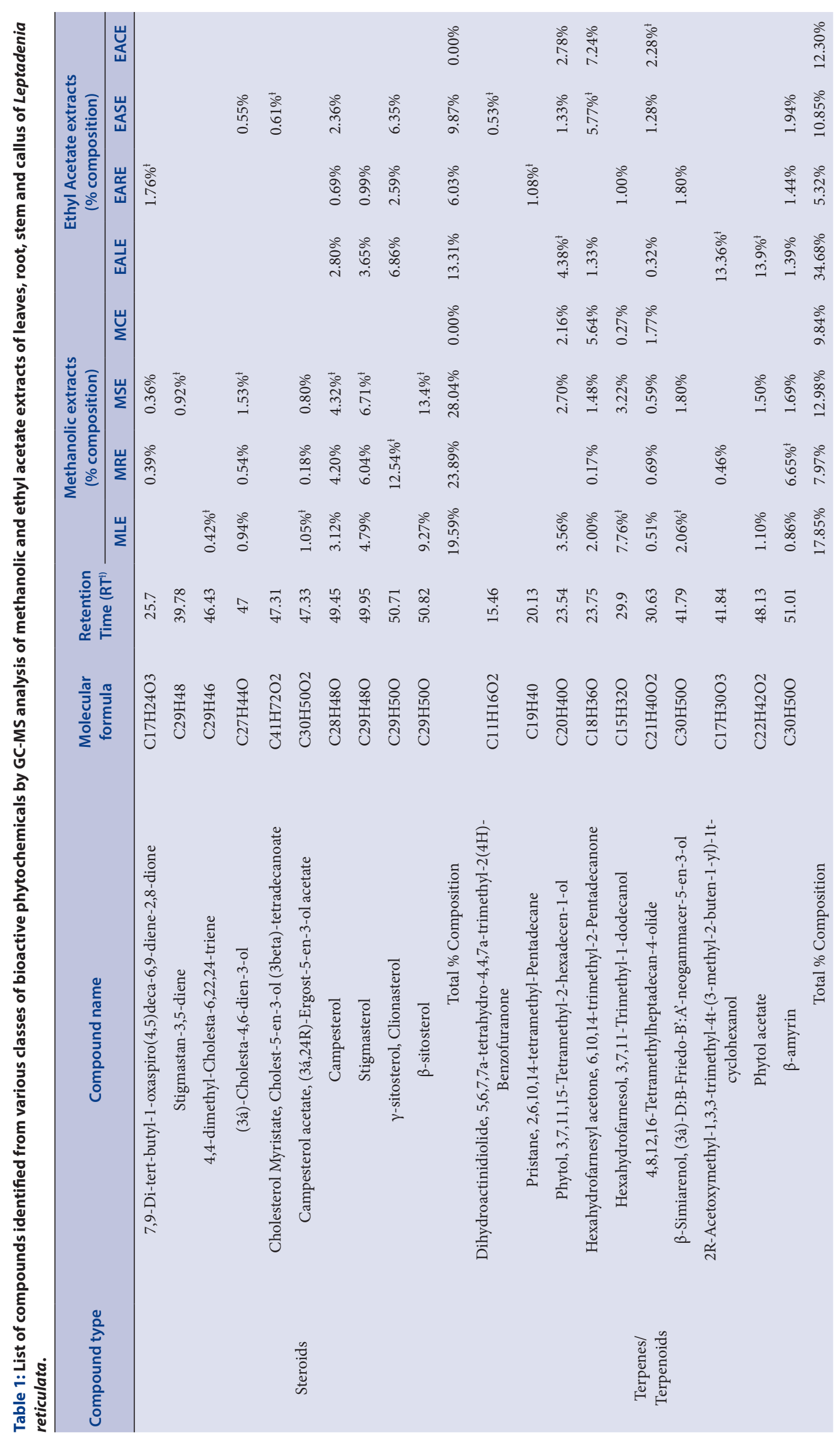




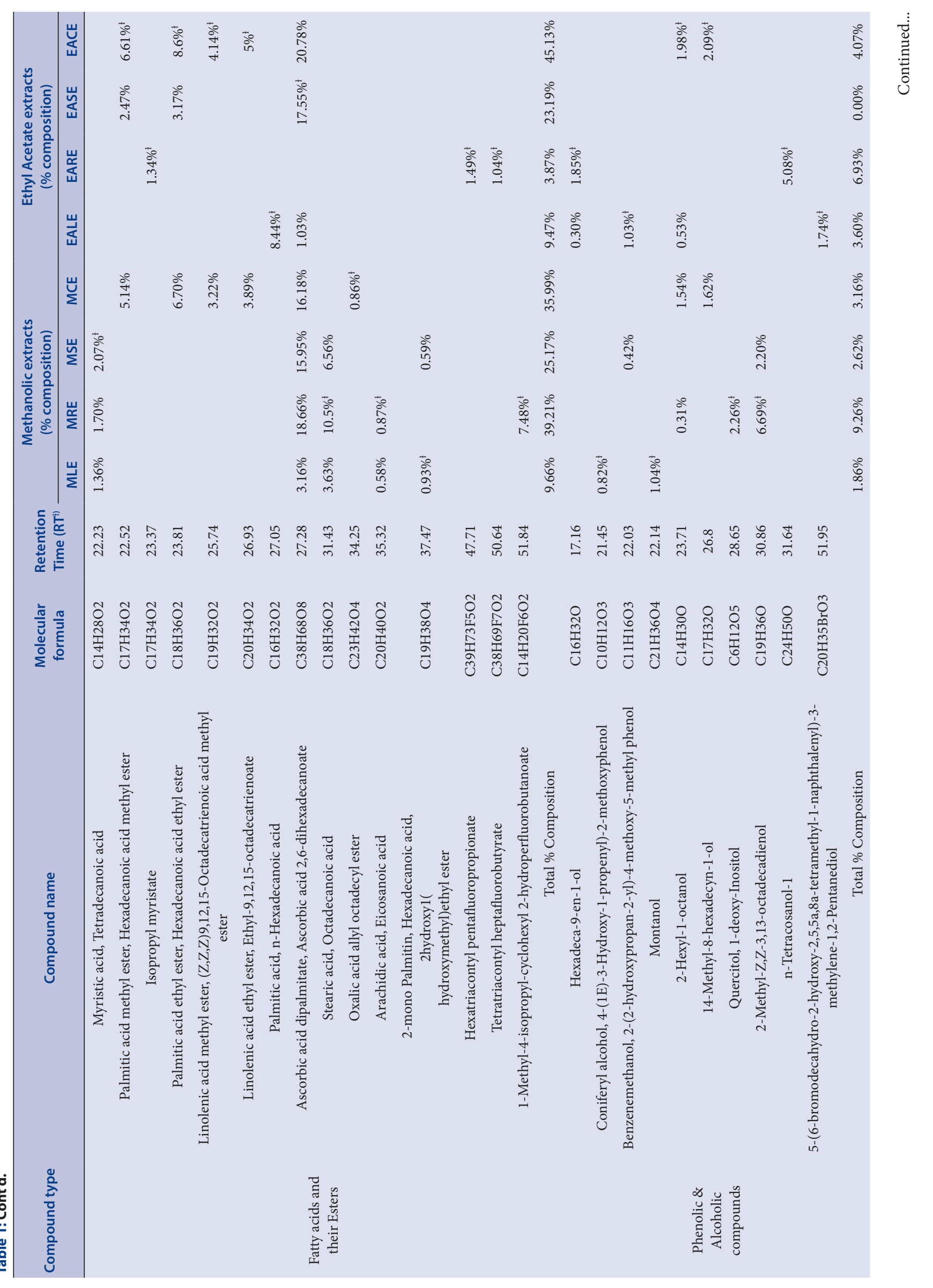




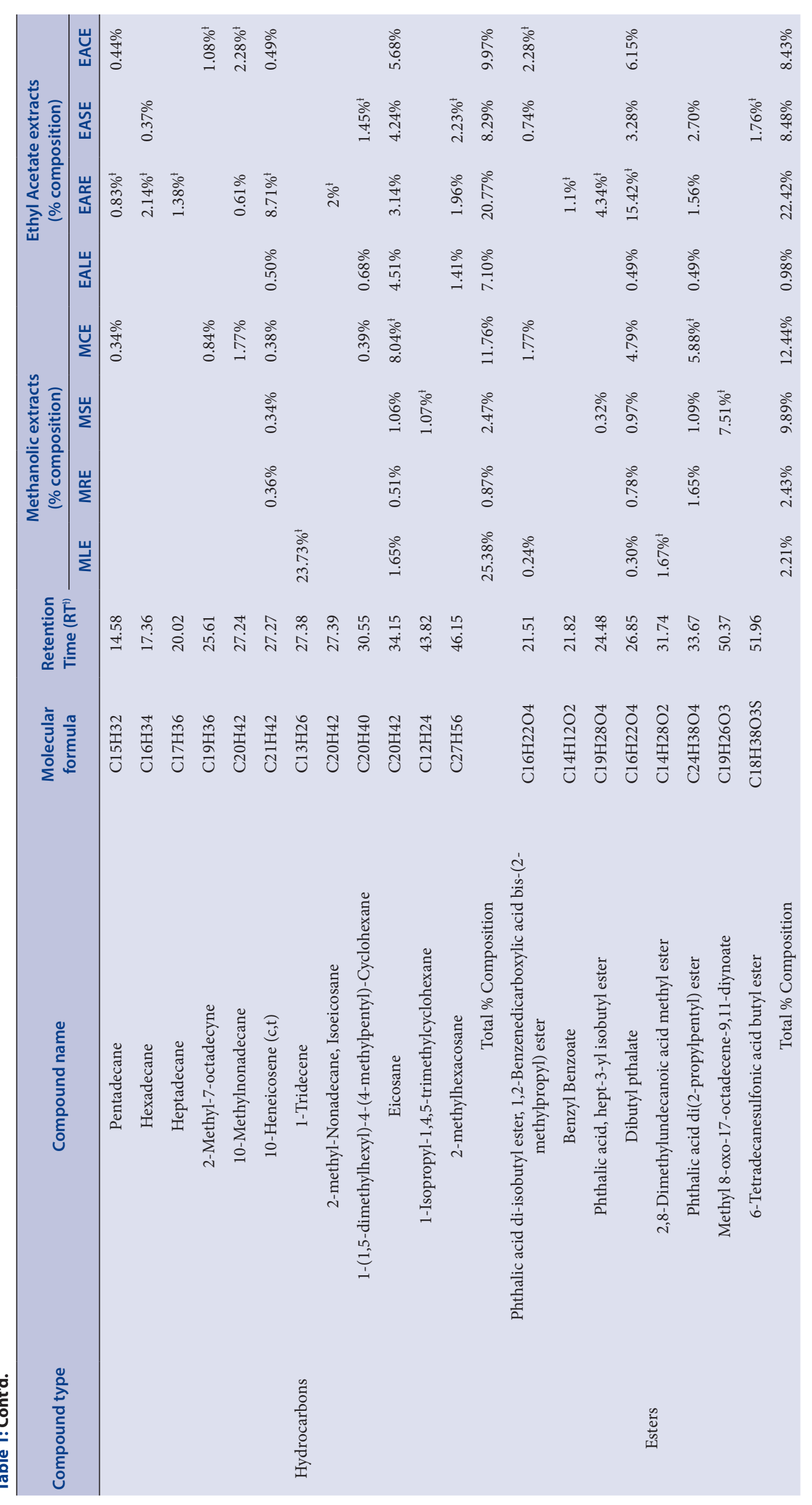




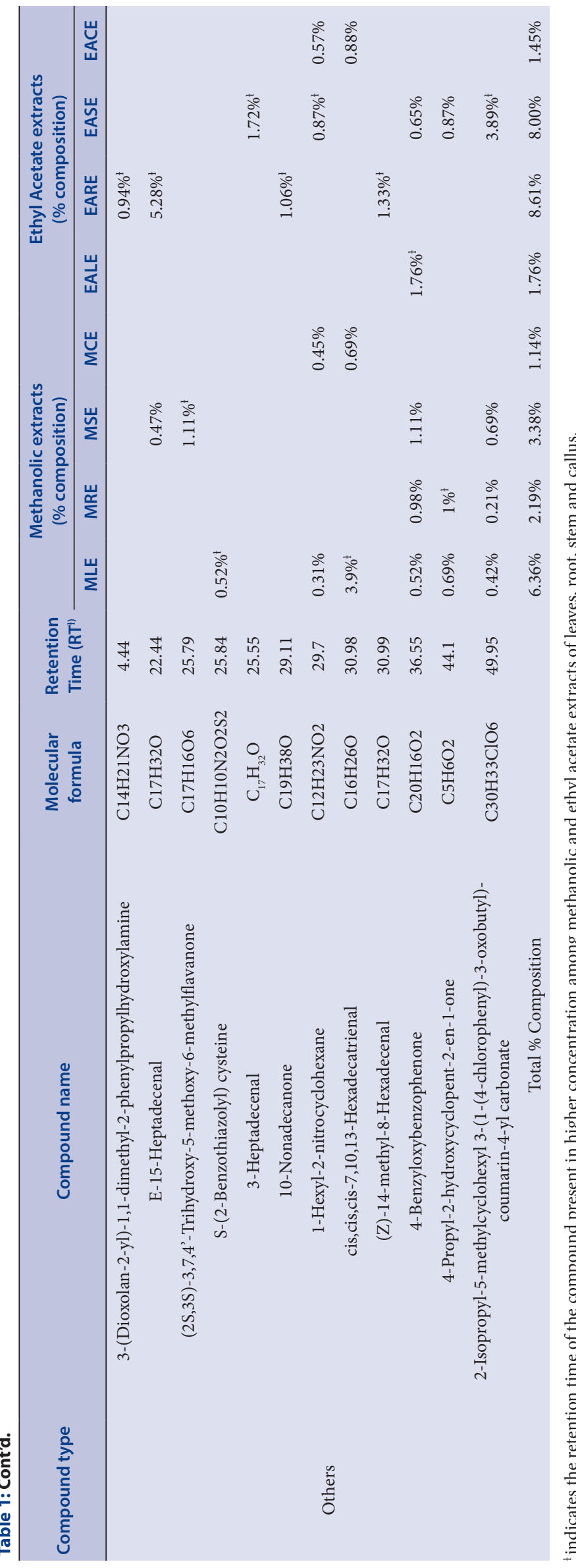

compound (2S,3S)-3,7,4'-Trihydroxy-5-methoxy-6-methylflavanone) and some other compounds like Heptadecane, Pentadecane, Hexadecane, E-15-Heptadecenal and S-(2-Benzothiazolyl) cysteine. The details of biological activity and uses of some important first time reported phytochemical compounds have been summarized in Table 2 .

\section{Steroids}

Steroids were present in different plant part extracts of $L$. reticulata in abundance and a total of 10 steroidal compounds were detected. Amongst all eight extracts highest amount of total steroidal content was detected in MSE (28.04\%) followed by MRE (23.89\%), MLE (19.59\%), EALE (13.31\%), EASE (9.87\%) and EARE (6.03\%). Steroidal compounds were surprisingly absent in both the callus extracts. Phytosterols were extracted in higher amounts in methanolic extracts. Phytosterols are very well known for their blood cholesterol lowering activity. ${ }^{25}$ Phytosterols have antifungal, antibacterial, antiulcerative, antitumoral, anti-inflammatory, anti-cancerous and anti-atherogenic activities. ${ }^{25-28}$ Stigmasterol was present in all plant parts but it was found absent in ethyl acetate stem extract and both the callus extracts. It was found in MSE (6.71\%), MRE (6.04\%), MLE (4.79\%), EALE (3.65\%) and EARE (0.99\%). Stigmasterol is an unsaturated phytosterol and has various medicinally important properties like cholesterol-lowering, anti-osteoarthritic, ${ }^{29}$ thyroid inhibitory, antiperoxidative, hypoglycemic, ${ }^{30}$ antihepatotoxic, anti-inflammatory, antinociceptive, antiviral, cancer-preventive activities and sedative effects. ${ }^{31}$ It is a strong antioxidant and shows antibacterial activity against multidrug resistant mycobacteria. ${ }^{32} \beta$-sitosterol was found in good quantities in methanolic stem $(13.40 \%)$ and root extracts $(9.27 \%)$. It was absent in all ethyl acetate extracts. $\beta$-sitosterol shows various biological activities like immunomodulatory, antioxidative, hepatoprotective activity ${ }^{33}$ and used in the treatment of benign prostatic hyperplasia. ${ }^{34} \beta$-sitosterol shows antiviral effect against Hepatitis B Virus, HIV virus and tobacco mosaic virus (TMV). ${ }^{33}$

First time reported from $L$. reticulata in this study, $\gamma$-sitosterol or Clionasterol was found in MSE (12.54\%), EALE (6.86\%), EASE (6.35\%) and EARE (2.59\%). $\gamma$-sitosterol shows anticancerous, ${ }^{35}$ hepatoprotective, anti-hyperglycemic activity and may act as a potential antidiabetic drug. ${ }^{36,37}$ The Presence of Campesterol is detected in L. reticulata for the first time in this study. It was found in MRE (12.54\%), EALE (6.86\%), EASE (6.35\%) and EARE (2.59\%). Campesterol is a cholesterol absorption reducing agent and shows anticancer and antioxidant activities. ${ }^{38}$ $\beta$-sitosterol and Campesterol are also used as biomarkers for cancer prevention. ${ }^{28}$ Cholesterol Myristate or Cholest-5-en-3-ol(3beta)-tetradecanoate is a cholesterol fatty acid ester and detected in ethyl acetate stem extract $(0.61 \%)$. Cholesterol Myristate is helpful in brain disease therapies, stem-cell transplantation, bone-marrow transplantation, treatment of bone diseases such as osteoporosis and chemotherapy. ${ }^{39,40}$ 7,9-Di-tert-butyl-1-oxaspiro(4,5)deca-6,9-diene-2,8-dione is a steroidal anti-mineralocorticoid and it was found in ethyl acetate root extract $(1.76 \%)$ and traces were found in MRE and MSE. Some other steroidal compounds detected in extracts of $L$. reticulata were Cholesta-4,6-dien3-ol (0.54-1.53\%), Campesterol acetate (Ergost-5-en-3-ol acetate) in MLE (1.05\%) and MSE (0.80\%), 4,4-dimethyl-Cholesta-6,22,24-triene in MSE (0.92\%) and Stigmastan-3,5-diene in MLE (0.42\%).

\section{Terpenes and Terpenoids}

Terpenes and terpenoids were abundantly present in the extracts of L. reticulata and 10 different terpene/terpenoid compounds were found. Amongst all eight extracts, the highest amount of total terpenes/ terpenoids was detected in EALE (34.68\%), then in MLE (17.85\%), MSE (12.98\%), EACE (12.30\%), EASE (10.85\%), MCE (9.84\%), MRE (7.97\%) and EARE (5.32\%). Overall, both the leaf extracts contained high amount of terpenes/terpenoids. Terpenes and terpenoids have attracted much 


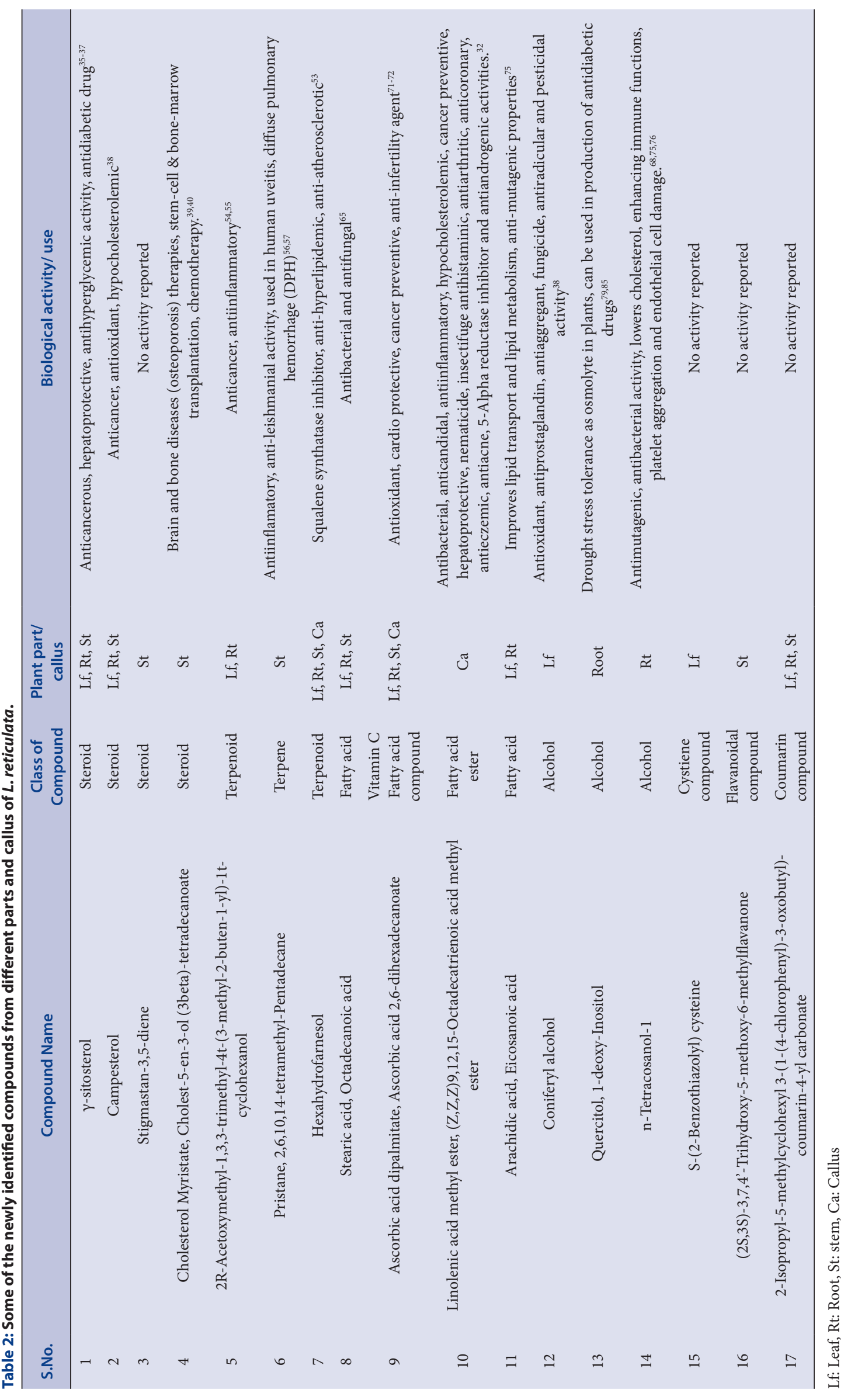


attention because of their important physiological and ecological roles and as defense compounds. ${ }^{41}$ They show biological activities like antioxidant, ${ }^{42}$ hepato-protective, ${ }^{43}$ and cholinesterase inhibitors. ${ }^{44} \beta$-amyrin was found in all plant part extracts (0.86-6.65\%) except for both callus extracts and highest amount was present in MRE (6.65\%). It is a pentacyclic triterpenol and have been reported for antioxidant, anti-apoptic, anti-inflammatory and anti-fibrotic activities. ${ }^{45,46} \beta$-simiarenol was found in MLE (2.06\%), MSE (1.80\%), EARE (1.80\%) and it was absent in callus extracts. It is a triterpenoid and showed in vitro leishmanicidal activity against Leishmania donovani promastigotes. ${ }^{47}$ Phytol was found in all extracts of EALE (4.38\%), MLE (3.56\%), EACE (2.78\%), MSE (2.70\%), MCE (2.16\%) and EASE (1.33\%) except for both the root extracts. Phytol is an important acyclic monounsaturated diterpene alcohol with various biological properties like anti-inflammatory, ${ }^{48}$ anti-cancer, ${ }^{49}$ antioxidant, ${ }^{50}$ diuretic, anti-allergic, immunostimulant, anti-trypanosomal, cholesterol lowering, antimicrobial activity against Mycobacterium tuberculosis and Staphylococcus aureus and used in antischistosomal therapy. ${ }^{51}$ Phytol acetate was found in highest amount in EALE (13.90\%), then MST $(1.50 \%)$ and MLE (1.10\%). It was found absent in root and callus extracts. Phytol acetate is also an acyclic diterpene alcohol and shows anti-inflammatory, anti-leishmanial activity. ${ }^{52}$ Hexahydrofarnesol or 3,7,11-trimethyl-1-dodecanol was found in highest amount in MLE (7.76\%), MSE (3.22\%), EARE (1.00\%) and traces were found in MCE. Hexahydrofarnesol is a sesquiterpenoid and acts as a squalene synthatase inhibitor which makes it an anti-hyperlipidemic and anti-atherosclerotic agent. ${ }^{53}$ 2R-Acetoxymethyl-1,3,3-trimethyl-4t-(3-methyl-2-buten-1-yl)$1 \mathrm{t}$-cyclohexanol was present in highest amount in EALE (13.36\%) and traces in MRE. It is a sesquiterpenoid and acts as an anticancer ${ }^{54}$ and potent anti-inflammatory agent. ${ }^{55}$ Pristane or 2,6,10,14-tetramethylPentadecane was found only in EARE (1.08\%). Pristane shows antiinflammatory activity and also has therapeutic uses in leishmania disese, human uveitis and diffuse pulmonary hemorrhage. ${ }^{56,57}$ Dihydroactinidiolide or 5,6,7,7a-tetrahydro-4,4,7a-trimethyl-2(4H)-benzofuranone was present in EASE (0.53\%). It is a monoterpenoid essential oil and it shows analgesic, antidiabetic, antibacterial and antifungal activities. ${ }^{32}$ Hexahydrofarnesyl acetone or 6,10,14-trimethyl-2-Pentadecanone is an isoprenoid ketone essential oil and it was found in highest amount in $\operatorname{EACE}(7.24 \%)$, EASE (5.77\%), MCE (5.64\%), MLE (2.00\%), MSE (1.48\%) and EALE (1.33\%). It was found in traces in both the root extracts. The 4,8,12,16-Tetramethylheptadecan-4-olide is an isoprenoid $\gamma$-lactone, it was found in all extracts except for EARE. The highest amount was present in both callus extracts EACE (2.28\%), MCE (1.77\%) and EASE (1.28\%).

\section{Fatty Acids and their Esters}

Fatty acids and their esters were present in abundance in different extracts of $L$. reticulata and 15 major different fatty acid compounds were found. The highest amount of total fatty acid and their ester compounds was found in EACE (45.13\%), MRE (39.21\%), MCE (35.99\%) followed by MSE (25.17\%), EASE (23.19\%), MLE (9.66\%), EALE (9.47\%) and EARE (3.87\%). Fatty acids are widely used as inactive ingredients (excipients) in drug preparations, cosmetics, fat emulsions, liposomes and also show antibacterial activity. ${ }^{58,59}$ Palmitic acid or $\mathrm{n}$-Hexadecanoic acid was found in MLE (8.44\%). It is a saturated fatty acid that has anti-androgenic, antifibrinolytic, hemolytic 5-alpha reductase inhibitor, antioxidant, hypo-cholesterolemic, ${ }^{60}$ anti-inflammatory, phospholipase inhibitor, ${ }^{61}$ anti-cancerous, ${ }^{62}$ antimicrobial, nematicide and mosquito larvicidal properties. ${ }^{63-65}$ Myristic acid and Stearic acid are saturated fatty acids and were detected in significant amounts only in methanolic leaf, stem and root extracts. Myristic acid or Tetradecanoic acid was found in MSE (2.07\%), MRE (1.70\%) and MLE (1.36\%). Myristic acid shows positive effects on HDL cholesterol and hence improving
HDL to total cholesterol ratio. ${ }^{66}$ It shows antioxidant, cancer preventive, ${ }^{63}$ antibacterial, antifungal, ${ }^{65}$ larvicidal, nematicide and repellent activity. ${ }^{63,67}$ Stearic acid or octadecanoic acid was found in MRE (10.50\%) and MLE (3.63\%) and it shows antimicrobial activity. ${ }^{65}$ Palmitic acid methyl ester or Hexadecanoic acid methyl ester was found in EACE (6.61\%), MCE (5.14\%) and EASE (2.47\%). It is a saturated fatty acid and shows antioxidant, antitumor, immunostimulant, chemopreventive and lipoxygenase inhibitory, ${ }^{32,68}$ antimicrobial activity and it is a potent mosquito larvicide. ${ }^{69,70}$ Similarly, Palmitic acid, ethyl ester or Hexadecanoic acid ethyl ester was found in EACE (8.60\%), MCE (6.70\%) and EASE (3.17\%). It has antioxidant, hemolytic, anti-androgenic, nematicide and pesticidal activities and also acts as 5-alpha reductase inhibitor. ${ }^{60}$ Vitamin $\mathrm{C}$ compound $1-(+)$-Ascorbic acid 2,6-dihexadecanoate was found in abundance in EACE (20.78\%), MRE (18.66\%), EASE (17.55\%), MCE (16.18\%). This shows potential antimicrobial, anti-cancerous ${ }^{71}$ and antioxidant activity. ${ }^{72}$ Linolenic acid methyl ester and Linolenic acid ethyl esters are polyunsaturated fatty acid esters and are present in good quantities only in both methanolic and ethyl acetate callus extracts. Linolenic acid ethyl ester or Ethyl-9,12,15-octadecatrienoate was found in EACE (5.00\%) and MCE (3.89\%). Linolenic acid ethyl ester act as acetylcholinesterase (AChE) inhibitor and can be used in neurodegenerative disorders treatment. ${ }^{73,74}$ Linolenic acid methyl ester or (Z, Z, Z) 9,12,15-Octadecatrienoic acid methyl ester was found in EACE (4.14\%) and MCE (3.22\%). It shows antibacterial, anticandidal, antiinflammatory, hypocholesterolemic, cancer preventive, hepatoprotective, nematicide, insectifuge, antihistaminic, antiarthritic, anticoronary, antieczemic, antiacne, 5-Alpha reductase inhibitor and antiandrogenic activities. ${ }^{32}$ Arachidic acid or Eicosanoic acid was found in MLE $(0.58 \%)$ and MRE $(0.87 \%)$. It is a saturated fatty acid involved in natural biological processes of transport and metabolism of lipids and shows anti-mutagenic properties. ${ }^{75}$ Overall, Fatty acids were present in abundance in callus extracts.

\section{Alcoholic and Phenolic Compounds}

There were 10 significant alcoholic and phenolic compounds identified in the extracts of both solvents. The highest amount of alcoholic compounds was found in root extracts of MRE (9.26\%) then in EARE (6.93\%), EACE (4.07\%), EALE (3.60\%) and MCE (3.16\%). Stem and leaf extracts contained lower amounts of alcoholic compounds. Phenolic compounds found in L. reticulata extracts were Coniferyl alcohol and 2-(2-hydroxypropan-2-yl)-4-methoxy-5-methyl phenol. Coniferyl alcohol was present in MLE $(0.82 \%)$ and it has been reported to show antioxidant, antiprostaglandin, antiaggregant, fungicide, antiradicular and pesticidal activity. ${ }^{38}$ The presence of another important alcoholic compound detected in EARE (5.08\%) was n-Tetracosanol-1. It is a fatty acid derivative of lignoceric acid and it shows antimutagenic ${ }^{75}$ and antibacterial activity. ${ }^{68} \mathrm{n}$-Tetracosanol-1 is one of the constituents of policosanol which modifies several cardiovascular disease risk factors by reducing LDL oxidation, platelet aggregation and endothelial cell damage. $^{76}$ 2-Methyl-Z,Z-3,13-octadecadienol was present in MRE (6.69\%) and MSE (2.20\%), it shows anticancer activity and increases zinc bioavailability. ${ }^{77}$ Trans-9-hexadecen-1-ol was found in EARE (1.85\%) and traces in EALE $(0.30 \%)$, it shows anti-inflammatory and anticancer activity. ${ }^{78}$ Quercitol or 1-deoxy Inositol is a cyclic polyalcohol found in MRE (2.26\%) which works as a powerful osmolyte and helps in drought stress tolerance in plants. ${ }^{79}$

\section{Hydrocarbons}

12 different hydrocarbon compounds were detected in different extracts of $L$. reticulata. The highest amount of hydrocarbons was present in MLE (25.38\%), followed by EARE (20.77\%), MCE (11.76\%), EACE (9.97\%), EASE (8.29\%), EALE (7.10\%), MSE (2.47\%) and traces were found in MRE. Different hydrocarbons were present in varying amounts in different 
extracts such as Pentadecane was found in traces in EARE $(0.83 \%)$, EACE (0.44\%) and MCE (0.34\%). Pentadecane exhibited antimicrobial activity against Leishmania infantum Promastigotes and Amastigotes parasites, antifungal activity against Fusarium oxysporum and antioxidant activity. ${ }^{68,80,81}$ In addition, Hexadecane was present in EARE $(2.14 \%)$ and EASE (0.37\%). Hexadecane shows antimicrobial and antioxidant activity. ${ }^{68}$ Another hydrocarbon Eicosane was present in all eight extracts with highest amounts in MCE (8.04\%) followed by EACE (5.68\%), EALE (4.51\%), EASE (4.24\%) and EARE (3.14\%). Eicosane shows antibacterial activity and also used in petrochemical industry. ${ }^{67} 10$-Heneicosene $(c, t)$ was found in traces in all the extracts except MLE and EASE, with highest amount in EARE (8.71\%). It can be used as aggregation pheromone for diptera. ${ }^{82}$ Heptadecane was found in EARE (1.38\%) that shows antiinflamatory, antimicrobial activities. ${ }^{68,83}$

\section{Esters}

A total of 8 ester compounds other than fatty acid esters were also detected and identified in varying composition in different extracts of EARE (22.42\%), MCE (12.44\%), MSE (9.89\%), EASE (8.48\%), EACE (8.43\%), MRE (2.43\%), MLE (2.21\%) and EALE (0.98\%). Among the detected fatty acid esters, Linolenic acid ethyl ester is used in the treatment of neurodegenerative disorders, ${ }^{73,74}$ and Linolenic acid methyl ester has shown properties like antimicrobial, nematicide, antihistaminic, antiinflammatory, anticancer, antiarthritic, anticoronary, hepatoprotective, antieczemic, antiacne and antiandrogenic activities. ${ }^{32}$

\section{Other Compounds}

Some other compounds of interest were found in different extracts like E-15-Heptadecenal was present in significant amounts in EARE $(5.28 \%)$ and it shows antibacterial ${ }^{84}$ and antioxidant activity. ${ }^{68}$ EARE contained Isopropyl myristate (1.34\%) used in cosmetic and topical medicinal preparations and also shows antioxidant and antibacterial activity. ${ }^{68}$ A coumarin compound 2-Isopropyl-5-methylcyclohexyl 3-(1-(4-chlorophenyl)-3-oxobutyl)-coumarin-4-ylcarbonate was found in EASE (3.89\%). MSE contained a flavanoidal compound (2S,3S)-3,7,4'Trihydroxy-5-methoxy-6-methylflavanone (1.11\%). Another compound of interest found in MLE was S-(2-Benzothiazolyl) cysteine.

\section{CONCLUSION}

Leptadenia reticulata (Jeevanti) is a traditional medicinal plant and found to be a rich source of bioactive phytochemicals possessing various biological activities. This study presented a comprehensive analysis of leaf, stem, root and callus extracts in methanol and ethyl acetate. The outcome of GC-MS analysis of this study, presented a detailed comparison of various classes of bioactive phytochemicals identified from different plant parts and callus. A comparative analysis of total 77 different bioactive compounds have been done and further discussed in details on the basis of potential biological role as well as medicinal importance. The present study has first time reported some potential bioactive phytochemicals in $L$. reticulata that includes $\gamma$-sitosterol, Campesterol, Pristane, Hexahydrofarnesol, Stearic acid, Arachidic acid, Coniferyl alcohol, n-Tetracosanol-1, Ascorbic acid 2,6-dihexadecanoate, (2S,3S)3,7,4'-Trihydroxy-5-methoxy-6-methylflavanone etc. As the medicinal value of similar bioactive components in other plant extracts are already proved, no wonder if these phytochemicals in L. reticulata may also have equal efficacy. It could be concluded that all eight extracts of $L$. reticulata contain significant abundance of various bioactive compounds from the various categories of bioactive compounds such as steroids, terpenes, fatty acids and their esters, alcoholic and phenolic compounds, hydrocarbons etc. The GC-MS analysis particularly of callus extracts showed high accumulation of fatty acids which was not generally seen in leaves that were used as explant. Further, this study may provide future prospects for isolation, biological and medicinal characterization of some more compounds from this plant.

\section{ACKNOWLEDGEMENT}

The authors express deepest sense of gratitude to Late Dr. D. V. Rao, Associate Professor, Department of Botany, University of Rajasthan, Jaipur whose blessings at every step have inspired to accomplish this work. Authors thank Arun Devana, USIC department, University of Rajasthan for providing access to GC-MS facility and helping in data acquisition. Authors acknowledge Central Instrumentation Facility at Department of Botany, University of Rajasthan, Jaipur.

\section{FINANCIAL SUPPORT}

This research was carried out using fellowship under scheme UGC-BSR [F.NO- 2009/219(BSR)] funded by UGC, India to P.G. This study was supported, in part, by contingency grant from DST-PURSE and UGCDRS-II Botany, University of Rajasthan, Jaipur.

\section{CONFLICT OF INTEREST}

The authors declare no conflict of interest.

\section{ABBREVIATIONS}

MLE: Methanolic Leaf Extract; MSE: Methanolic Stem Extract; MRE: Methanolic Root Extract; MCE: Methanolic Callus Extract; EALE: Ethyl Acetate Leaf Extract; EASE: Ethyl Acetate Stem Extract; EARE: Ethyl Acetate Root Extract; EACE: Ethyl Acetate Callus Extract.

\section{REFERENCES}

1. Sofowora A, Ogunbodede E, Onayade A. The role and place of medicinal plants in the strategies for disease prevention. Afr J Tradit Complement Altern Med. 2013;10(5):210-29

2. Gupta D, Kumar M. Evaluation of in vitro antimicrobial potential and GC-MS analysis of Camellia sinensis and Terminalia arjuna. Biotechnology Reports. 2017;13:19-25.

3. World Health Organization, Geneva. WHO Traditional Medicine Strategy 20142023. Geneva: World Health Organization. 2013

4. Altemimi A, Lakhssassi N, Baharlouei A, Watson DG, Lightfoot DA. Phytochemicals: Extraction, Isolation and Identification of Bioactive Compounds from Plant Extracts. Plants (Basel). 2017;6(2):42.

5. Rungsung W, Ratha K, Dutta S, Dixit AK, Hazra J. Secondary metabolites of plants in drugs discovery. World Journal of Pharmaceutical Research. 2015;4:604-13.

6. Yuan H, Ma Q, Cui H, Liu G, Zhao X, LiW, et al. How Can Synergism of Traditional Medicines Benefit from Network Pharmacology? Molecules. 2017;22(7):1135.

7. Shekhawat NS. Establishment and economic evaluation of micropropagated Jeewanti (Leptadenia reticulata) plants in field. Natural Product Radiance. 2006;5(4):311-4

8. Godara P, Rao DV, Dulara B, Barwer N. Multidimensional approach of endangered ayurvedic plant Leptadenia reticulata: A review. Int J Appl Sci Eng Res. 2015:4:531-43.

9. Mohanty SK, Swamy MK, Sinniah UR, Anuradha M. Leptadenia reticulata (Retz.) Wight and Arn. (Jivanti): Botanical, Agronomical, Phytochemical, Pharmacological and Biotechnological Aspects. Molecules. 2017;22(6):1019.

10. Bawra B, Dixit M, Chauhan NS, Dixit VK, Saraf D.K. Leptadenia reticulata a RasayanaHerbs: A Review. Asian Journal of Plant Sciences. 2010;9:314-9.

11. Schmelzer GH, Gurib-Fakim A. Plant resources of tropical Africa 11(2): Medicinal plants 2. PROTA Foundation. 2013;158-9.

12. Philips FS. Clinicnl trial with Leptaden for recurrent and threatened abortions and premature labour. Curr Med Pract. 1977;21:317-20.

13. Baig MI, Bhagwat VG. Study the efficacy of Galactin Vet Bolus on milk yield in dairy cows. Vet World. 2009;2:140-2.

14. Rani S, Manavalan R, Kilimozhi D, Balamurugan K. Preliminary study on antiimplantation activity of Leptadenia reticulata in female rats. Int $\mathrm{J}$ Pharm Tech Res. 2009;1:1403-5

15. Natarajan V, Dhas ASAG. Phytochemical Composition and in vitro Antimicrobial, Antioxidant Activities of Ethanolic Extract of Leptadenia reticulata [W and $A$ ] Leaves. Middle East J Sci Res. 2014;21:1698-705. 
16. Sathiyanarayanan L, Sinnathambi A, Chidambaranathan A. Anticarcinogenic activity of Leptadenia reticulata against Daltons ascitic lymphoma. Iran J Pharmacol Ther. 2007;6:133-5.

17. Pravansha S, Thippeswamy BS, Veerapur VP. Immunomodulatory and antioxidant effect of Leptadenia reticulata leaf extract in rodents: Possible modulation of cell and humoral immune response. Immunopharm Immunot. 2012;34:1010-9.

18. Pushpa KB, Mahipal RR, Manasa VB, Mohan BT, Ranganayakulu D. Antiepileptic activity and neuropharmacological screening of methanolic extract of Leptadenia reticulata against different experimental models. J Adv Drug Res. 2010;1:1-8.

19. Sneha B, Ganga RM, Divya N. Evaluation of Antipyretic and Anti-Inflammatory Activity of Aqueous Extract of Leptadenia reticulata in Animal Models. J Nat Remedies. 2016;16:40-4

20. Nema AK, Agarwal A, Kashaw V. Screening of hepatoprotective potential of Leptadenia reticulata stems against paracetamol-induced hepatotoxicty in rats. Int J Res Pharm Biomed Sci. 2011;2:666-71.

21. Bodhanapu S, Sreedhar S, Rupeshkumar M, Tamizhmani PP, Satya KB, Mohamed NK. Antiulcer activity of aqueous extract of Leptadenia reticulata leaves. Inventi Rapid Ethnopharmacolog. 2011;2:1190-6.

22. Rajpurohit B, Gilhotra UK, Verma AK, Genwa C. Evalution of anxiolytic activity of Leptadenia reticulata plant. Int J Pharm Sci Res. 2016;7(12):5099.

23. Mohanraj S, Santhoshkumar C, Chandran A. Diuretic activity of whole plant extract of Leptadenia reticulata. Res J Pharmacol Pharmacodyn. 2012;4:84-6.

24. Wakade AS, Juvekar AR, Hole RC, Nachankar RS, Kulkarni MP. Antioxidant and cardioprotective effect of Leptadenia reticulata against adriamycin-induced myocardial oxidative damage in rat experiments. Planta Med. 2007:73(09):443.

25. Othman RA, Moghadasian MH. Beyond cholesterol-lowering effects of plant sterols: clinical and experimental evidence of anti-inflammatory properties. Nutr Rev. 2011;69(7):371-82.

26. Awad AB, Downie A, Fink CS, Kim U. Dietary phytosterol inhibits the growth and metastasis of MDA-MB-231 human breast cancer cells grown in SCID mice. Anticancer Res. 2000;20:821-4.

27. Berger A, Jones PJ, Abumweis SS. Plant sterols: factors affecting their efficacy and safety as functional food ingredients. Lipids Health Dis. 2004;3:5.

28. Li JH, Awad AB, Fink CS, Wu YW, Trevisan M, Muti P. Measurement variability of plasma beta-sitosterol and campesterol, two new biomarkers for cancer prevention. Eur J Cancer Prev. 2001;10(3):245-9.

29. Gabay O, Sanchez C, Salvat C, Chevy F, Breton M, Nourissat G, et al. Stigmasterol: a phytosterol with potential anti-osteoarthritic properties. Osteoarthritis Cartilage. 2010;18(1):106-16.

30. Panda S, Jafri M, Kar A, Meheta BK. Thyroid inhibitory, antiperoxidative and hypoglycemic effects of stigmasterol isolated from Butea monosperma. Fitoterapia. 2009;80(2):123-6.

31. Beckstrom-Sternberg SM, Duke JA. CRC handbook of medicinal mints (aromathematics): phytochemicals and biological activities. CRC press, Inc, USA. 1996;409-17.

32. Mujeeb F, Bajpai P, Pathak N. Phytochemical evaluation, antimicrobial activity and determination of bioactive components from leaves of Aegle marmelos. Biomed Res Int. 2014;1-11.

33. Parvez MK, Alam P, Arbab AH, Al-Dosari MS, Alhowiriny TA, Alqasoumi SI. Analysis of antioxidative and antiviral biomarkers $\beta$-amyrin, $\beta$-sitosterol, lupeol, ursolic acid in Guiera senegalensis leaves extract by validated HPTLC methods. Saudi Pharm J. 2018;26(5):685-93

34. Wilt TJ, MacDonald R, Ishani A. beta-sitosterol for the treatment of benign prostatic hyperplasia: a systematic review. BJU Int. 1999;83(9):976-83

35. Sundarraj S, Ramar T, Sreevani V, Kaveri K, Gunasekaran $P$, Achiraman $S$, et.al. gamma-Sitosterol from Acacia nilotica L. induces G2/M cell cycle arrest and apoptosis through c-Myc suppression in MCF-7 and A549 cells. Journal of Ethnopharmacology. 2012;141:803-9.

36. Balamurugan R, Duraipandiyan $\mathrm{V}$, Ignacimuthu S. Antidiabetic activity of $\gamma$-sitosterol isolated from Lippia nodiflora L. in streptozotocin induced diabetic rats. European Journal of Pharmacology. 2011;667(1-3):410-8.

37. Balamurugan $R$, Stalin A, Ignacimuthu S. Molecular docking of $\gamma$-sitosterol with some targets related to diabetes. Eur J Med Chem. 2012;47(1):38-43.

38. U.S. Department of Agriculture, Agricultural Research Service. 1992-2016 Dr. Duke's Phytochemical and Ethnobotanical Databases. [updated 2017 october 18; cited 2018 August 14]. Available from: https://phytochem.nal.usda.gov/.

39. Chen DF, Cao JH, Liu Y, Wu Y, Du SH, Li H, et al. BMP-ld pathway targeted by cholesterol myristate suppresses the apoptosis of PC12 cells. Brain Res. 2011;1367:33-42.

40. Chen DF, Zhang HL, Du SH, Li H, Zhou JH, LiYW, et al. Cholesterol myristate suppresses the apoptosis of mesenchymal stem cells via upregulation of inhibitor of differentiation. Steroids. 2010;75(13-14):1119-26.

41. Jiang Z, Kempinski C, Chappell J. Extraction and Analysis of Terpenes/Terpenoids Current Protocols in Plant Biology. 2016;1:345-58.

42. Gonzalez-Burgos E, Gomez-Serranillos MP. Terpene compounds in nature: a review of their potential antioxidant activity. Curr Med Chem. 2012;19(31):5319-41.

43. Xu GB, Xiao YH, Zhang QY, Zhou M, Liao SG. Hepatoprotective natural triterpenoids. Eur J Med Chem. 2018;145:691-716
44. Burcul F, Blazevic I, Radan M, Politeo O. Terpenes, Phenylpropanoids, Sulfur and Other Essential Oil Constituents as Inhibitors of Cholinesterases. Current Medical Chemistry. 2018;25:1.

45. Okoye NN, Ajaghaku DL, Okeke HN, Ilodigwe EE, Nworu CS, Okoye FB. betaAmyrin and alpha-amyrin acetate isolated from the stem bark of Alstonia boone display profound anti-inflammatory activity. Pharm Biol. 2014;52(11):1478-86.

46. Thirupathi A, Silveira PC, Nesi RT, Pinho RA. $\beta$-Amyrin, a pentacyclic triterpene, exhibits anti-fibrotic, anti-inflammatory and anti-apoptotic effects on dimethyl nitrosamine-induced hepatic fibrosis in male rats. Hum Exp Toxicol. 2017; 36(2):113-22.

47. Amin E, Moawad A, Hassan H. Biologically-guided isolation of leishmanicidal secondary metabolites from Euphorbia peplus L. Saudi Pharm J. 2017;25(2):236-40.

48. Silva RO, Sousa FBM, Damasceno SR, Carvalho NS, Silva VG, Oliveira FR, et al. Phytol, a diterpene alcohol, inhibits the inflammatory response by reducing cytokine production and oxidative stress. Fundamental and Clinical Pharmacology. 2014;28(4):455-64.

49. Lee K, Rhee S, Park K. Anticancer activity of phytol and eicosatrienoic acid identified from perilla leaves. J Korean Soc Food Sci Nutrition. 1999;28(5):1107-12.

50. Santos CC, Salvadori MS, Mota VG, Costa LM, de Almeida AA, de Oliveira GA, et al. Antinociceptive and Antioxidant Activities of Phytol in vivo and in vitro Models. Neurosci J. 2013;1-9.

51. De Moraes J., de Oliveira RN, Costa JP, Junior ALG, de Sousa DP, Freitas RM, et al. Phytol, a Diterpene Alcohol from Chlorophyll, as a Drug against Neglected Tropical Disease Schistosomiasis Mansoni. Geary TG, ed. PLoS Neglected Tropical Diseases. 2014;8(1):2617.

52. Al-Marzoqi A, Hadi M, Hameed I. Determination of metabolites products by Cassia angustifolia and evaluate antimicobial activity. Journal of Pharmacognosy and Phytotherapy. 2016;8:25-48.

53. Montellano PR, Wei JS, Castillo R, Hsu CK, Boparai A. Inhibition of squalene synthetase by farnesyl pyrophosphate analogues. J Med Chem. 1977;20(2):243-9

54. Naine SJ, Devi CS, Mohanasrinivasan V, Doss CG, Kumar DT. Binding and molecular dynamic studies of sesquiterpenes (2R-acetoxymethyl-1,3,3-trimethyl-4t-(3-methyl-2-buten-1-yl)-1t-cyclohexanol) derived from marine Streptomyces sp. VITJS8 as potential anticancer agent. Appl Microbiol Biotechnol. 2016;100(6):2869-82.

55. Anupama N, Madhumitha G, Rajesh KS. Role of Dried Fruits of Carissa carandas as Anti-Inflammatory Agents and the Analysis of Phytochemical Constituents by GC-MS. BioMed Research International. 2014;1-6.

56. Daudin JB, Monnet D, Kavian N, Espy C, Wang A, Chereau C, et al. Protective effect of pristane on experimental autoimmune uveitis. Immunol Lett. 2011;141(1):83-93

57. Mbati PA, Abok K, Orago AS, Anjili CO, Kagai JM, Githure JI, et al. Pristane $(2,6,10,14$-Tetramethyl-pentadecane) inhibits disease progression in Leishmaniainfected Balb/c mice. Afr J Health Sci. 1994;1(4):157-9.

58. Rustan AC, Drevon CA. Fatty Acids: Structures and Properties. In: eLS. John Wiley and Sons Ltd, Chichester. 2005.

59. Abdel-Aal El, Haroon AM, Mofeed J. Successive solvent extraction and GC-MS analysis for the evaluation of the phytochemical constituents of the filamentous green alga Spirogyra longata. The Egyptian Journal of Aquatic Research. 2015;3:233-46.

60. Gavamukulya Y, Abou-Elella F, Wamunyokoli F, El-Shemy HA. GC-MS Analysis of Bioactive Phytochemicals Present in Ethanolic Extracts of Leaves of Annona muricata: A Further Evidence for Its Medicinal Diversity. Pharmacognosy Journal. 2015:7(5):300-4.

61. Aparna V, Dileep KV, Mandal PK, Karthe P, Sadasivan C, Haridas M. Anti-inflammatory property of $n$-hexadecanoic acid: structural evidence and kinetic assessment. Chem Biol Drug Des. 2012;80(3):434-9.

62. Pascual G, Avgustinova A, Mejetta S, Martín M, Castellanos A, Attolini CS, et al. Targeting metastasis-initiating cells through the fatty acid receptor CD36. Nature. 2017;541(7635):41-5.

63. Selvamangai G, Bhaskar A. GC-MS analysis of phytocomponents in the methanolic extract of Eupatorium triplinerve. Asian Pacific Journal of Tropical Biomedicine. 2012;2(3):1329-32

64. Perumalsamy $H$, Jang M, Kim JR, Murugan K, Ahn YJ. Larvicidal activity and possible mode of action of four flavonoids and two fatty acids identified in Millettia pinnata seed toward three mosquito species. Parasites and Vectors. 2015;8(1):237.

65. Agoramoorthy G, Chandrasekaran M, Venkatesalu V, Hsu MJ. Antibacterial and antifungal activities of fatty acid methyl esters of the blind-your-eye mangrove from India. Brazilian Journal of Microbiology. 2007;38(4):739-42.

66. Noto D, Fayer F, Cefalu AB, Altieri I, Palesano O, Spina R, et al. Myristic acid is associated to low plasma HDL cholesterol levels in a Mediterranean population and increases HDL catabolism by enhancing HDL particles trapping to cell surface proteoglycans in a liver hepatoma cell model. Atherosclerosis. 2016:246:50-6.

67. Sivakumar R, Jebanesan A, Govindarajan M, Rajasekar P. Larvicidal and repellent activity of tetradecanoic acid against Aedes aegypti (Linn.) and Culex quinquefasciatus (Say.) (Diptera: Culicidae). Asian Pac J Trop Med. 2011;4(9):706-10. 
68. Faridha Begum I, Mohankumar R, Jeevan M, Ramani K. GC-MS Analysis of Bio-active Molecules Derived from Paracoccus pantotrophus FMR19 and the Antimicrobial Activity Against Bacterial Pathogens and MDROs. Indian Journal of Microbiology. 2016;56(4):426-32.

69. Komansilan A, Abadi AL, Yanuwiadi B, Kaligis DA. Isolation and Identification of Biolarvicide from Soursop (Annona muricata Linn) Seeds to Mosquito (Aedes aegypti) Larvae. International Journal of Engineering and Technology. 2012;12(03):28-32

70. Chandrasekaran M, Senthilkumar A, Venkatesalu V. Antibacterial and antifungal efficacy of fatty acid methyl esters from leaves of Sesuvium portulacastrum $\mathrm{L}$. Eur Rev Med Pharmcol. Sci. 2011:15:775-80.

71. Karthikeyan SC, Velmurugan S, Donio MB, Michaelbabu M, Citarasu T. Studies on the antimicrobial potential and structural characterization of fatty acids extracted from Sydney rock oyster Saccostrea glomerata. Ann Clin Microbiol Antimicrob. 2014;13:332.

72. Huang B, Ban X, He J, Tong J, Tian J, Wang Y. Comparative analysis of essential oil components and antioxidant activity of extracts of Nelumbo nucifera from various areas of China. J Agric Food Chem. 2010;58(1):441-8.

73. Suganthy N, Karutha PS, Pandima DK. Cholinesterase Inhibitors from Plants: Possible Treatment Strategy for Neurological Disorders- A Review. International Journal of Biomedicine and Pharmaceutical Sciences. 2009;3:87-103.

74. Colovic MB, Krstic DZ, Lazarevic-Pasti TD, Bondzic AM, Vasic VM. Acetylcholinesterase Inhibitors: Pharmacology and Toxicology. Current Neuropharmacology. 2013;11(3):315-35

75. Makhafola TJ, Elgorashi EE, McGaw LJ, Awouafack MD, Verschaeve L, Eloff JN Isolation and characterization of the compounds responsible for the antimutagenic activity of Combretum microphyllum (Combretaceae) leaf extracts. BMC Complementary and Alternative Medicine. 2017;17(1):446.

76. Janikula M. Policosanol: a new treatment for cardiovascular disease? Altern Med Rev. 2002;7(3):203-17.
77. Hase GJ, Deshmukh KK, Pokharkar RD, Gaje TR, Phatangre ND. Phytochemical Studies on Nerium oleander L. Using GC-MS. International Journal of Pharmacognosy and Phytochemical Research. 2017:9(6):885-91.

78. Ghate NB, Das A, Chaudhuri D, Panja S, Mandal N. Sundew plant, a potential source of anti-inflammatory agents, selectively induces G2/M arrest and apoptosis in MCF-7 cells through upregulation of p53 and $\mathrm{Bax} / \mathrm{Bcl}-2$ ratio. Cell Death Discov. 2016;2:15062

79. Arndt SK, Livesley SJ, Merchant A, Bleby TM, Grierson PF. Quercitol and osmotic adaptation of field-grown Eucalyptus under seasonal drought stress. Plant Cell Environ. 2008;31(7):915-24

80. Bruno F, Castelli G, Migliazzo A, Piazza M, Galante A, Lo Verde V, et. al. Cytotoxic Screening and in vitro Evaluation of Pentadecane Against Leishmania infantum Promastigotes and Amastigotes. J Parasitol. 2015;101(6):701-5.

81. Yuan J, Raza W, Shen Q, Huang Q. Antifungal activity of Bacillus amyloliquefaciens NJN-6 volatile compounds against Fusarium oxysporum f. sp. cubense. Appl Environ Microbiol. 2012;78(16):5942-4.

82. Gary JB, Richard GV. Insect Pheromone Biochemistry and Molecular Biology: The Biosynthesis and Detection of Pheromones and Plant Volatiles. Academic press, Elsevier, Inc. 2003;232.

83. Kim DH, Park MH, Choi YJ, Chung KW, Park CH, Jang EJ et. al. Molecular study of dietary heptadecane for the anti-inflammatory modulation of NF-kB in the aged kidney. PLoS One. 2013;8(3):59316.

84. Supardy A, Ibrahim D, Sulaiman S, Aili ZN. Inhibition of Klebsiella pneumoniae ATCC 13883 Cells by Hexane Extract of Halimeda discoidea (Decaisne) and the Identification of Its Potential Bioactive Compounds. Journal of Microbiology and Biotechnology. 2012;22:872-81.

85. Worawalai W, Rattanangkool E, Vanitcha A, Phuwapraisirisan P, Wacharasindhu S Concise synthesis of $(+)$-conduritol $F$ and inositol analogues from naturally available (+)-proto-quercitol and their glucosidase inhibitory activity. Bioorganic and Medicinal Chemistry Letters. 2012;22(4):1538-40.
GRAPHICAL ABSTRACT

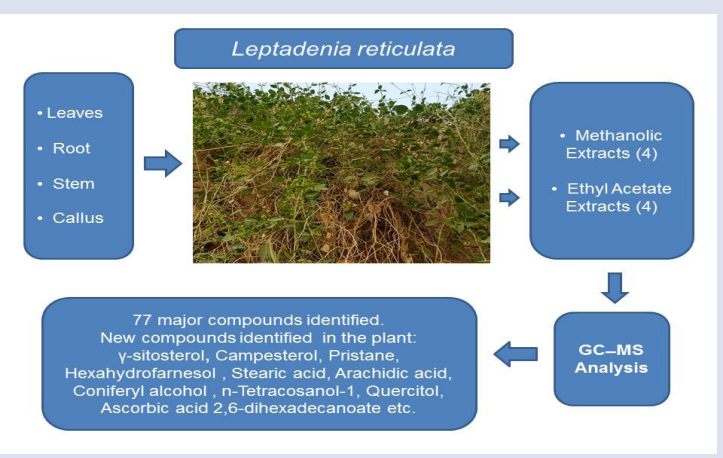

\section{SUMMARY}

- This study presented a comprehensive GC-MS analysis of Bioactive phytochemicals of leaves, stem, root and callus extracts in methanol and ethyl acetate from Leptadenia reticulata, locally known as Jeevanti. The outcome of this study presented a detailed comparison of 77 different bioactive phytochemicals belonging to various classes of compounds and further discussed in details on the basis of potential biological role as well as medicinal importance. The present study has first time reported some potential bioactive phytochemicals in L. reticulata that includes $\gamma$-sitosterol, Campesterol, Pristane, Hexahydrofarnesol, Stearic acid, Arachidic acid, Coniferyl alcohol, n-Tetracosanol-1, Ascorbic acid 2,6-dihexadecanoate, (2S,3S)-3,7,4'-Trihydroxy-5-methoxy6-methylflavanone etc.

\section{ABOUT AUTHORS}

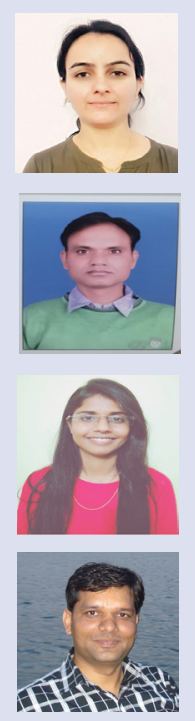

Priyanka Godara is a Research Scholar and pursuing Ph.D. in Lab No. 05, Department of Botany, University of Rajasthan, Jaipur, India.

Bunty Kumar Dulara is a Research Scholar and pursuing Ph.D. in Lab No. 05, Department of Botany, University of Rajasthan, Jaipur, India.

Neelam Barwer is a Research Scholar and pursuing Ph.D. in Lab No. 05, Department of Botany, University of Rajasthan, Jaipur, India.

Dr. Navneet Singh Chaudhary is working as Assistant Professor at Department of Botany, University of Rajasthan, Jaipur, India. He is working in the area of Plant Biochemistry, Protein Biology and Molecular Biology of plants.

Cite this article: Godara P, Dulara BK, Barwer N, Chaudhary NS. Comparative GC-MS Analysis of Bioactive Phytochemicals from Different Plant Parts and Callus of Leptadenia reticulata Wight and Arn. Pharmacog J. 2019;11(1):129-40. 